This item was submitted to Loughborough's Research Repository by the author.

Items in Figshare are protected by copyright, with all rights reserved, unless otherwise indicated.

\title{
Contributing factors in construction accidents
}

PLEASE CITE THE PUBLISHED VERSION

PUBLISHER

(C) Elsevier

VERSION

AM (Accepted Manuscript)

LICENCE

CC BY-NC-ND 4.0

REPOSITORY RECORD

Haslam, Roger, Sophie Hide, Alistair G.F. Gibb, Diane E. Gyi, Trevor C. Pavitt, Sarah Atkinson, and Roy Duff. 2019. "Contributing Factors in Construction Accidents". figshare. https://hdl.handle.net/2134/5941. 
This item was submitted to Loughborough's Institutional Repository (https://dspace.lboro.ac.uk/) by the author and is made available under the following Creative Commons Licence conditions.

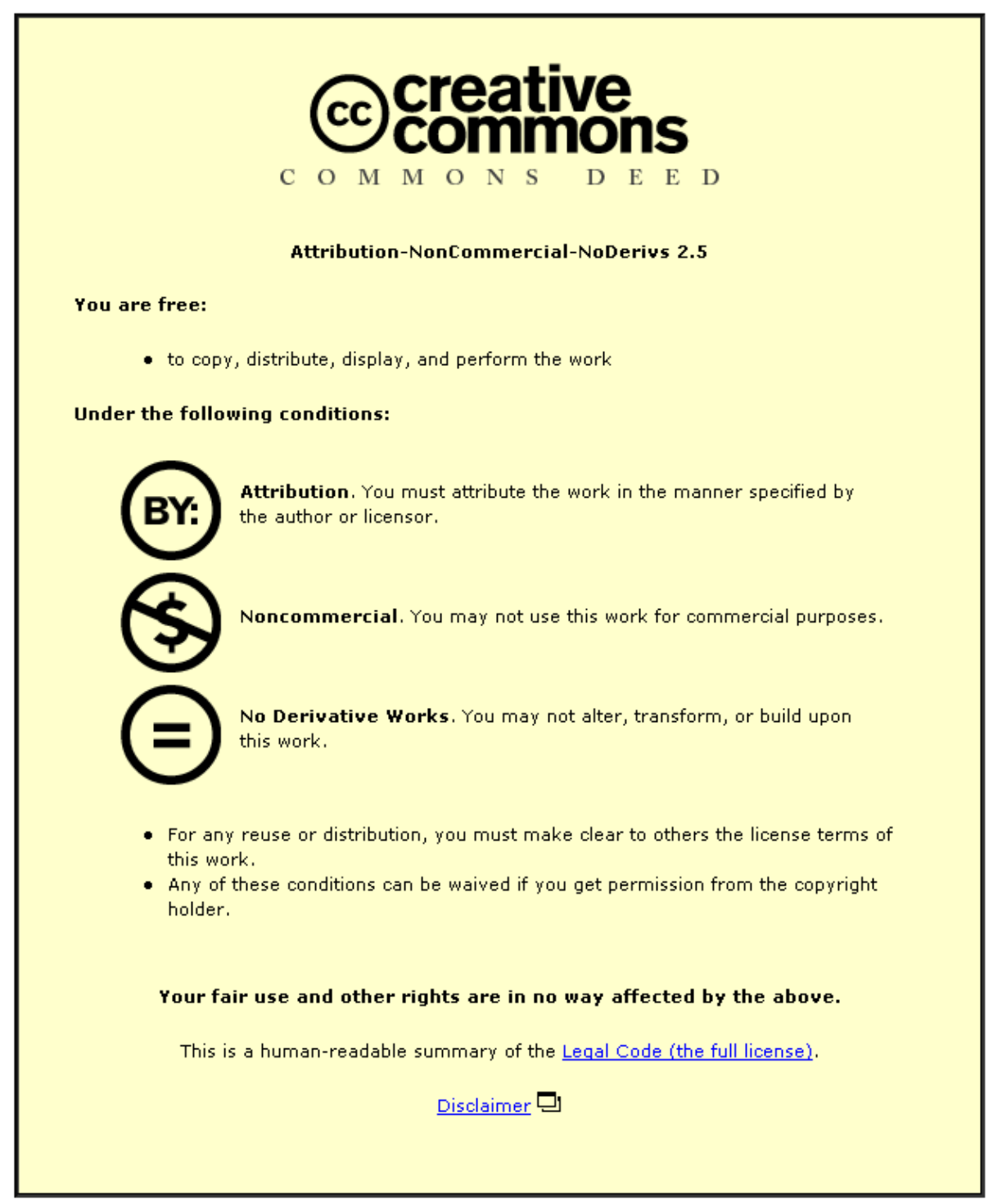

For the full text of this licence, please go to: http://creativecommons.org/licenses/by-nc-nd/2.5/ 


\section{Contributing Factors in Construction Accidents}

R A Haslam ${ }^{\mathrm{a}^{*}}$, S A Hide ${ }^{\mathrm{a}}$, A G F Gibb ${ }^{\mathrm{b}}$, D E Gyi ${ }^{\mathrm{a}}$, T Pavitt ${ }^{\mathrm{b}}$, S Atkinson ${ }^{\mathrm{a}}$ and A R Duff ${ }^{\mathrm{c}}$

${ }^{a}$ Health \& Safety Ergonomics Unit, Department of Human Sciences, Loughborough University, Leicestershire, LE11 3TU

${ }^{\mathrm{b}}$ Department of Civil and Building Engineering, Loughborough University, Leicestershire, LE11 3TU

${ }^{\mathrm{c}}$ Manchester Centre for Civil and Construction Engineering, UMIST, PO Box 88 Manchester M60 1QD

* corresponding author (R.A.Haslam@lboro.ac.uk) 


\section{Abstract}

This overview paper draws together findings from previous focus group research and studies of 100 individual construction accidents. Pursuing issues raised by the focus groups, the accident studies collected qualitative information on the circumstances of each incident and the causal influences involved. Site based data collection entailed interviews with accidentinvolved personnel and their supervisor or manager, inspection of the accident location, and review of appropriate documentation. Relevant issues from the site investigations were then followed up with off-site stakeholders, including designers, manufacturers and suppliers. Levels of involvement of key factors in the accidents were: problems arising from workers or the work team (70\% of accidents), workplace issues (49\%), shortcomings with equipment (including PPE) (56\%), problems with suitability and condition of materials (27\%), and deficiencies with risk management (84\%). Employing an ergonomics systems approach, a model is proposed, indicating the manner in which originating managerial, design and cultural factors shape the circumstances found in the work place, giving rise to the acts and conditions which, in turn, lead to accidents. It is argued that attention to the originating influences will be necessary for sustained improvement in construction safety to be achieved.

Keywords: injury prevention; accident investigation; risk management 


\section{Introduction}

The poor safety performance of the construction industry continues to give international cause for concern. Although the record in Great Britain is reasonable by international standards, the industry still accounts for one third of all work fatalities, with a similar poor performance for injuries and ill health (HSC, 2003). While there has been a modest decline in fatalities over recent years (rate of 4 per 100,000 workers), when collated with those in all industries, construction accounted for $31 \%$ of all work related deaths in 2002/03. The majority of construction fatalities in this year resulted from falls from height (46\%) and struck by a moving vehicle (15\%).

Major injury rates in Great Britain for construction have, however, risen over the most recent two years for which data are available, from 356 per 100,000 employees in 2001/02 to 375 in 2002/03. Although this increase follows three years in which the major injury rate has shown a slight decline, an increase of 5\%, back to the level recorded five years ago, is a matter of concern. The most common causes of major injuries were falls from height (31\%); slips, trips or falls on the level (25\%); and being struck by a moving/falling object (17\%). Other papers in this special issue of Applied Ergonomics (eg Hoonakker et al, 2004; Chi et al, 2004) describe the situation in other countries, revealing a similar pattern.

Although figures for fatalities are accurate, surveys commissioned by the Health and Safety Executive (HSE) indicate a reporting rate by employers for other reportable injuries as low as 40\% (HSC, 2003). Thus, the published statistics are the tip of the iceberg. The safety problem described above has characterised the industry for decades suggesting that lessons 
from the past have still to be learnt. Accidents in the construction industry represent a substantial ongoing cost to employers, workers and society.

Appreciation of the causes of occupational accidents has benefited from research attention over many years (Heinrich, 1980). Contemporary commentators point to the systemic nature of safety failures and wide reaching contributory factors (Kletz, 2001). Reason (1995) highlighted the pathway from latent, organisational failures (eg poor design or planning decisions), to the conditions where active failures (workplace errors and violations) can occur. Rasmussen (1997) presented a review of alternative conceptual approaches to modelling risk, safety and accidents. From this, Rasmussen argued the case for an approach that recognises the complexity of socio-technical work systems, focussing more on the mechanisms generating organisational and individual behaviour in actual, dynamic work contexts, rather than narrow attention to errors in tasks and acts. Implicit in the ideas of Reason and Rasmussen, is the fundamental involvement of human factors/ergonomics in most safety failures.

Modelling of the causal processes of accidents and injuries in the construction industry is less mature, with previous research largely confined to the collection, analysis and interpretation of data derived from regulatory accident reporting schemes (eg Hinze and Russell, 1995; Hunting et al, 1994; Kisner and Fosbroke, 1994; and Snashall, 1990). This approach is limited by problems with data collection (eg under reporting) and the broad classifications used for coding. Problems of this nature were reported again by BOMEL (2001) in a more recent analysis of RIDDOR data (HSE, 1996) available for Great Britain. Looking at the data collected by construction companies themselves, previous work by Gyi et al (1999) found the 
quality of the reporting processes to be poor, coupled with a failure to collate and undertake effective analysis of the data that are collected.

HSE $(1978,1988)$ used case study procedures to examine fatal accidents and identified causes such as failure to ensure safe systems of work, poor maintenance, use of defective materials, and poor supervision and training. However, the reports concentrated on fatal accidents and it is probable there are differences in the aetiology of non-fatal accidents (Saloniemi and Oksanen, 1998). Whittington et al (1992) is one of the few other studies that has attempted to undertake in-depth analysis of accidents in the industry. Their findings identified a range of headquarter, site and individual factors in accidents examined, approximately in the ratio 1:2:1. Whittington et al acknowledged limitations of their work due to the relatively small number of accidents investigated (30) and incomplete information in the accident records. In addition, there have been important changes affecting safety management since Whittington et al's research, particularly in connection with the implementation of European Directive 92/57/EEC, requiring attention be given to safety within construction design and management processes (HSC, 2001).

In a UMIST study, examining behaviour modification approaches to improving construction safety, Duff et al (1994) developed a safety audit checklist, used to monitor safety performance of construction sites. Further work by Suraji et al (2001) at UMIST led to a model of risk factors for accidents in construction operations. The UMIST model distinguishes between problems with operator actions, site conditions and construction practices, and linkage of these with project, contractor and process management influences. In recognising that project concept, design and management factors are frequently an origin of site based failures, Suraji \& Duff's approach has been a significant development on other 
theoretical 'root cause' models that confine their attention to site personnel, their behaviour and actions (Gibb et al, 2001; Suraji and Duff, 2001).

In summary, while there is good understanding of the extent and pattern of accidents in the construction industry, there has only been limited investigation regarding the full range of contributory managerial, site and individual factors. With this background, the research presented here sought to describe the wide range of factors involved in construction accidents. Specific aims were to:

1. identify the immediate events in a sample of 100 non-fatal construction accidents that either caused or had the potential to cause injury

2. collect information on the circumstances that allowed these accident events to occur

3. collate this information with the findings from previous focus group research, to explain the processes of accident causation, including the contribution of management, project, site and individual factors

4. suggest the lessons that should be learnt to improve construction safety

As presented at the $3^{\text {rd }}$ Ergonomics in Building and Construction Symposium, Seoul, August 2003, the intention of this paper is to provide an overview of the findings and recommendations from the full research (Loughborough University and UMIST, 2003). The sections which follow present details of the research investigations and a summary of descriptive results from studies of individual accidents. A model of causal influences is then proposed summarising the research findings. This is followed by explanation and discussion of the model components, drawing upon information from the focus group and accident study research. 


\section{Research Investigations}

The investigation used a combination of focus group (reported in detail elsewhere by Hide et al, 2001; Loughborough University and UMIST, 2003) and accident study research. Seven focus groups (a form of group interview involving several participants) were held at the commencement of the project, with a wide range of stakeholders from the industry, to scope issues for subsequent attention. Each group was asked to consider where safety failure occurs and why accidents still happen in construction. The accident studies then examined the issues raised by the focus groups, through in-depth investigation of 100 accidents, as soon as possible after each incident had occurred. Examination of off-site influences on the accidents was achieved through accident-specific (investigation of paths of causality in individual accidents) and accident-independent (expert opinion on generic issues) approaches, where accident-specific investigation was not feasible.

\subsection{Accident Study Sampling}

One hundred accidents were studied in detail. Access to accidents was obtained through organisations that had already agreed to participate in the research, via companies contacting the project team in response to project publicity, and through approaches to industry contacts known to the researchers. Sampling was on a pragmatic quota basis, with the aim of achieving a spread of accidents across the two high level dimensions of construction build and accident category. These two dimensions were identified as being of primary interest as construction design, processes, management and safety culture vary considerably between Engineering, Civil Engineering, Major Building and Residential construction sectors. Causal mechanisms in accidents differ according to accident type, with manual handling injuries having a different pattern of causation to being struck by a moving vehicle, for example. The sample size was insufficient to allow further stratification by other variables. 
For legal reasons, the research was restricted to accidents that were not subject to investigation by HSE, limiting the investigation to less serious incidents in terms of injury outcome (injury outcome, rather than injury potential). Other inclusion criteria were that the accident had occurred within the preceding two months, and that the accident victim (or involved person) and supervisor/manager were still on site and willing to participate in the research.

\subsection{Accident study procedures}

Site-based data collection entailed interviews with accident-involved personnel and their supervisor or manager, inspection of the accident site (where this still existed), and review of relevant documentation, such as accident notification form, risk assessment and method statements ${ }^{1}$. A report of the site-based findings was then prepared and reviewed by an expert pairing of a construction and ergonomics (human factors) specialist from within the research team (ie the authors of this paper) . The expert pairing suggested areas for further follow-up examination. Where possible, issues identified by the expert pairing were pursued directly with the designers, manufacturers, suppliers and managers relevant to the incident. In many of the studies, however, this proved impossible due to difficulty identifying the appropriate individuals to contact and then securing their cooperation in assisting with the research. In these cases, the issues were discussed with other industry professionals, independent of the accident, but qualified by virtue of their expertise to comment on the circumstances.

\footnotetext{
${ }^{1}$ EC Framework Directive 89/391/EEC established a legal requirement in European Union countries for employers to undertake assessments with respect to risks to safety and health. Method statements, setting out how a construction job or process is to be carried out, are not a legal requirement in Great Britain, but are considered to be good practice. Method statement and risk assessment documentation is often combined.
} 


\subsection{Descriptive results from Accident Studies}

Table 1 presents the target and achieved sample across four categories of construction buildtypes, as covered by this study. Many of the main principal contractors operating in Great Britain were represented. Table 2 indicates the extent to which the sampling strategy of obtaining a spread of accident types against RIDDOR ${ }^{2}$ (HSE, 1996) categories, was achieved. HSE data for the four-year period 1996-2000 formed the basis of this (eg as published by HSC, 2003). Tables 1 and 2 demonstrate that the sample achieved a reasonable spread across the primary dimensions of interest. Deviation from the sampling targets was due to the heavy reliance on cooperation from the industrial collaborators needed to undertake the research and the access to accidents they were able to provide.

Tables 1 and 2 about here

There was wide variation in the nature of build and organisational details of participating sites, ranging from short contract work to major building projects, being undertaken over a number of years. All but 16 of the sites were brownfield (previously developed land), with 4 unknown/missing data. Sites varied considerably in size, accommodating between 7-2500 personnel and with build schedules varying between 1 week to more than 10 years. From the 100 accidents, 71 projects were reported to be running to time, 1 was ahead and 18 were behind schedule (10 unknown/missing data). Four of the sites were undertaking concurrent phases of work, whereas 11 were in the 'start' phase, 58 in the 'middle', 9 between 'middle'

\footnotetext{
${ }^{2}$ RIDDOR is the statutory injury and dangerous occurrences reporting scheme operating in Great Britain and the distribution of accident types obtained through RIDDOR is the best estimate available of the pattern of accidents occurring in the construction industry.
} 
and 'end', 7 in the 'end' and 2 in the 'after' phase (9 unknown/missing data). The remaining 4 projects were refurbishment. This information is relevant in terms of placing the study sample in context and demonstrating its representativeness. Each of the variables mentioned affect the nature of the construction workplace, the way in which it is managed and the risks present.

Details of the 100 individuals most directly involved in each accident are summarised in table 3. This was either the injured person or, in the case of non-injury incidents, the most immediate witness.

Table 3 about here

Due to the need to avoid incidents subject to HSE investigation, most of the accidents did not have serious injury outcomes. However, following an analysis of the possible consequences of each accident by the research team (Loughborough University and UMIST, 2003), more than a third were judged to have had the potential to result in a fatality, while more than two thirds could have led to a serious injury (eg fracture, amputation, penetrating eye injury), figure 1 . The 'likely outcomes' in figure 1 would have required only a minor change in circumstances; 'possible outcomes’ would have needed a number of circumstances to have been different, but with it possible that this could have occurred. On this basis, it is argued it is reasonable to generalise the findings of causation from this sample to more serious accidents.

Figure 1 about here 
The pattern of involvement of tools, equipment and materials / structures, along with the nature of the task or activity being undertaken at the time of the accident is presented in Table 4. The distinction between 'tools' and 'plant/equipment' is that tools refers to smaller assistive aids, typically used by just one or two operatives at a time; plant/equipment refers to more substantive machinery. The category 'materials' covers supplies used in the building fabrication, eg cement, timber, bricks or building blocks etc. The column in Table 4 labelled 'site/structure' indicates accidents where an aspect of the construction site or building structure was a primary causal agent in the incident.

Table 4 about here

An analysis of the factors involved in each accident was performed by the researchers, based on their judgement of 'reasonable confidence' that a factor was present in an accident (table 5). It should be borne in mind when interpreting the results of this analysis that it is easier to be confident concerning the involvement of more immediate factors, eg worker actions or site hazards, than less tangible influences, such as safety culture.

Table 5 about here

\section{Hierarchy of causal influences}

Drawing together the findings from the focus groups and accident studies, a model is proposed, suggesting a hierarchy of causal influences in construction accidents, Figure 2. The approach taken with the model reflects of the views of those such as Kletz (2001) and Svedung and Rasmussen (2002), who have highlighted the inadequacy of deterministic, 
causal accident models when dealing with highly adaptive socio-technical systems, such as found in construction.

Thus, the model shown in Figure 2 describes how accidents arise from a failure in the interaction between the work team, workplace, equipment and materials, giving rise to the 'immediate accident circumstances’. The double arrows at the centre of Figure 2 represent multiple two-way interactions. The operation of the worker, site and material/equipment factors in leading to (or precluding) an accident depends in turn on proximal influences, labelled here as 'shaping factors'. For example, the actions, behaviour, capabilities and communication of the work team are affected by or shaped by their attitudes, motivations, knowledge, skills, supervision, health and fatigue. The workplace is affected by site constraints, work scheduling and housekeeping. The suitability, usability, condition and, therefore, safety of materials and equipment depend on their design, specification and supply/availability. These shaping factors are then subject to more distal 'originating influences', including the permanent works design, project management, construction processes, safety culture, risk management, client requirements, economic climate and education provision. Vignettes 1 and 2 illustrate the possible involvement of influences in the model in example accidents from the research. The following sections discuss the elements of the model in further detail.

Figure 2 about here

Vignettes 1 to 2 about here 


\section{Explanation and Discussion of Model Components}

\subsection{Immediate Accident Circumstances and Shaping Factors}

The causal analysis presented in table 5 demonstrates that, not surprisingly, the actions of individuals and site hazards featured in many of the 100 accidents examined. It was interesting that many of the accidents occurred 'off-task', either during preparatory activities or when individuals were moving around site. Also noteworthy was the high prevalence of material and equipment factors as accident causes, although it is possible the incidence of these within the sample may have been affected by the concentration of the research on 'minor' accidents. In these cases, deficiencies with material or equipment design, or their actual condition at the time of the accident, contributed to the failure. In many situations, the safety of those needing to handle the materials or use the equipment appeared to have been given little consideration by those responsible for their design, supply or purchase.

\section{Worker and workteam factors}

Problems arising from workers (defined broadly to include all site-based personnel) or the work team, especially worker actions or behaviour and worker capabilities, were judged to have been involved in over two thirds (70\%) of the accidents (table 5). This compares with the 70-80\% level described by Rasmussen (1997) as typically found by accident reviews. In this context, it is relevant to note Reason's point that unsafe acts, just as much as their less frequent bad outcomes, are consequences as much as causes in the accident chain of events (Reason, 1995). The explanations from the accident study interviews and focus groups for construction workers engaging in unsafe acts were three-fold:

- safety being overlooked in the context of heavy workloads and other priorities 
- taking shortcuts to save effort and time

- inaccurate perception of risk, with feelings of invulnerability and 'it won't happen to me'

Underlying each of these are inadequate safety knowledge, pointing to deficiencies with education and training. A distinction should be made between education and training. Education imparts high level knowledge and skills, transferable to different situations. Training is more context specific, dealing with procedures or rules for undertaking particular tasks or activities. Effective education equips individuals with the ability to analyse a situation and respond accordingly. Training, however, provides more directive instruction as to how an act should be performed. A combination of both education and training is desirable.

With regard to the training provided at present, the accident studies suggested the effectiveness of this is questionable when it comes to health and safety.

"The crane co-ordinator course I had was not training - it was just here's the form, fill it out and sign it.” (46 year old maintenance inspector, accident 38)

Interviewees indicated that safety training is often delivered by rote, by trainers with a poor understanding of learning and skill acquisition. Site inductions and tool box talks are examples of situations where this occurs.

“They're not any value [site inductions] when you've had so many - I just need to know if the site varies from others. They're not really to do with scaffolder's work." (31 year old scaffolder, accident 18)

It should be no surprise if such training fails to engage its recipients and it may well be harmful in the negative attitudes instilled towards safety. Where learning takes place 'on the 
job’, this is likely to disseminate and perpetuate bad habits. Little health and safety education appeared to have been provided for those at supervisory, managerial or professional levels, let alone for site operatives.

Previous research has identified the important influence front line supervisors have on safety. It has long been argued that the supervisor, or front-line manager, is a key individual in accident prevention, having daily contact with staff and the opportunity to control the unsafe conditions and acts leading to accidents (Heinrich et al, 1980; Chew, 1988; Simard and Marchand 1994). The literature suggests that the important aspects of supervisory behaviour in this respect include: attitudes and approaches to safety and training, nature and extent of interaction with employees, and thoroughness and willingness to learn from accident investigation.

Information from the 100 accident studies suggests that front line supervisors in construction typically undertake very limited safety-related activity. There were few instances of supervisors or operatives under their direction being able to describe examples of supervisory safety activity. In a number of studies, the supervisor had been complicit in safety violations. It was apparent from the interviews that construction supervisors frequently have little safety awareness and a poor understanding of accident causation and prevention. This is not surprising given the lack of safety education discussed above. Coupled with this is the perceived conflicting priority of meeting project deadlines and a lack of positive incentives for individuals in a supervisory role to prioritise safety. In practice, working safely often means working efficiently and coincides with good project and work management. 
The problems with health monitoring of construction workers is widely recognised (Gyi et al, 1998; HSE, 2002). For operatives, in particular, this research indicated again that there is rarely any effective pre-employment screening or health surveillance. This is in the context of physically demanding work, with inherent health risks. The incidents examined by this research included at least two where a pre-existing health problem (musculoskeletal in both instances) either contributed to or was made worse by the accident.

It is also apparent from this research that construction workers work long hours (table 3). This might be the result of paid overtime for operatives or, in the case of managerial or professional staff, regarded as necessary due to a high work load. Although few direct linkages were found in the accident studies between tiredness or fatigue and specific failures, some accident-involved individuals had been working very long periods without a break, or several long days without a day off. The consequences of tiredness and fatigue are reduced concentration, poor decision making and, it might be expected, compromised safety.

Language difficulties were rarely an obvious factor in the accident studies, the following example being an exception:

"I had a full trolley of plasterboard and was wheeling it along the gangway with help from a foreign labourer. There were communication problems. If the other man could have understood 'stop pushing' instantly it probably would have helped prevent the accident.” (30 year old ceiling fixer, accident 22)

It does seem likely that a poor command of the local language could impair safety (as well as productivity) in situations where coordination is required. The interviews indicated that 
language abilities appear to be assessed only informally (if at all) when individuals are recruited for work, with no explicit consideration of the implications for safety.

In other instances, poor communication within work teams contributed to incidents. In some cases this was due to the physical distance between work colleagues or high levels of background noise. This is likely to be a function of work planning and supervision as well as education and training. In situations where the importance of communication and coordination can be recognised in advance, technological solutions, making use of compact, wearable 2-way radio devices, for example, might be a solution.

Problems with communication also arose at an organisational level. The fire in one accident happened due to deficient communications with the gas supplier, who had apparently given confirmation that the gas supply was off in properties undergoing renovation. The communication problems were compounded by poor safety procedures, which allowed the communication failure to go unchecked. An observation made here is that in some circumstances, undue reliance is placed on informal communication, when the safety risk is such that a much more robust safe system of work ought to be in place.

\section{Workplace factors}

Workplace factors, most notably poor housekeeping and problems with the site layout and space availability, were considered to have contributed in half (49\%) of the accident studies. Local hazards on site were a feature in many of the 100 accidents. Problems included slip and trip hazards, such as trailing cables, uneven ground or debris, and muddy conditions. 
"There is always brick dust, which is a slip hazard, but when block work is cut the debris is like roller-balls under your feet.” (45 year old electrical supervisor, accident 51).

Other accidents involved injury from protruding hazards such as nails or scaffolding components. These were often coupled with a lack of clearly defined walkways and poor housekeeping.

"If the points had been marked or coloured then I could have seen them better, but they are steel discs, which is like a camouflage." (36 year old charge hand pipe fitter, accident 64)

It was very noticeable to the non-construction members of the research team how poor the situation is in these respects on most construction sites, even those considered to be 'well run' by industry standards. Industry representatives respond to this criticism, arguing that difficult conditions are inevitable given the constantly changing workplace and work activities that occur on construction sites. However, pointing to the improved performance in site management on some engineering construction projects counters this view. From the perspective of those familiar with safety in a wide range of other industries, poor site conditions found in construction appear to be a symptom of the weak safety and risk management culture in the industry.

Site constraints, typically inadequate space or difficult access to perform a task, were identified as being involved in $15 \%$ of the accident studies. In one of the more serious cases, insufficient room to extend stabilisers led to a delivery vehicle partially overturning. In this 
case, as in most of the others where site constraints were involved, inadequate planning coupled with poor local assessment of risk were probably key contributors to the incident.

Problems associated with outdoor working are frequently cited as one of the unusual aspects of construction, affecting the safety record of the industry. However, weather appeared to be a factor in only a small number of the accident studies, despite the data collection for the research spanning all seasons.

\section{Materials and equipment}

Shortcomings with equipment, including personal protective equipment (PPE), were identified in over half (56\%) of the incidents. Deficiencies with the suitability and condition of materials, including packaging, featured in more than a quarter (27\%) of incidents. Hazards were either inherent to the materials, as with the extremely heavy $140 \mathrm{~kg}$ steel angles that were manoeuvred by hand in one incident, or due to problems with the way the materials were supplied, for example steel banding around plywood, which led to an arm laceration.

"There were ten steel angles [weighing $140 \mathrm{~kg}$ each] to be unloaded from the forklift truck onto the storage point on the floor... with a man at each end we expected to take about 20 minutes to do this.” (19 year old panel fixer, accident 5)

Materials packaging can also cause problems with disposal, leading to other hazards introduced onto site (eg fall or fire hazards).

Suppliers have paid attention to the manual handling requirements of some materials, through the introduction of smaller cement bags, for example. Unfortunately, this approach does not seem to have extended far, even with widely used generic items, concrete kerbs for example 
(Bust et al, 2004). There are situations where alternatives are available, but not in use due to custom and practice, cost or availability. In one accident, an operative was carrying a reel of rebar tie wire, which caught on an obstacle and hit the individual in the eye when it released. The operative mentioned that he had worked on sites abroad where the tie wire came in convenient dispensing canisters, but that he had not seen these in the UK. There are many situations where modest changes to materials or the way in which they are supplied could improve safety. However, at present, purchasers are not prioritising safety as a criterion. Without this, suppliers have no encouragement to be innovative.

Similar issues exist with equipment and tools as with materials. A number of the accidents featured scaffolding. Some of the incidents involved falls through a scaffold, or problems when negotiating openings from one level to the next. Injuries in several accidents arose from individuals striking their head or other body parts against scaffolding protrusions.

Scaffolding strike hazards arise from the manner in which scaffolding is assembled, either due to poor configuration, site constraints or equipment limitations. Accident study follow-up work attempted to explore the scaffolding design alternatives that might exist or be under development that could alleviate some of the indirect hazards arising from scaffolding. Unfortunately, the research team was not able to obtain relevant information from scaffolding manufacturers or suppliers as those approached felt unable to comment. Although the design of scaffold towers, in terms of their convenience for erection and use, has received some attention, there is little evidence that ergonomics aspects of traditional scaffolding have been examined. This is another opportunity for modest innovation.

Discussions with interviewees in the accident studies revealed that tools are usually selected on the basis of price and performance. Durability may sometimes be a consideration but 
usability and safety do not appear to be purchasing factors. A number of the accidents featured tools or equipment in poor condition. It is to be expected that shared equipment, having multiple users, will be subject to heavy wear and tear. In such circumstances, scheduled inspection and maintenance are important, although there was little evidence of this in practice.

Despite a wide reliance on PPE as a control measure, this study again highlights the problems with such equipment. Much of the PPE found in use on construction sites at present is uncomfortable and interferes with the wearer's ability to perform their work. It is incongruous that in some instances the PPE itself resulted in accidents. In two cases, the injured person's hard hat fell off; both then struck their head on an object when they stood up from bending down to recover it. In two other cases, safety harnesses for working at height caught on surrounding items, causing an arm fracture in one accident and a back injury in another.

“With the hat you're more likely to hit your head, as you don't account for the extra height when walking underneath different structures.” (56 year old foreman, accident 52)

Problems with PPE mean that it is often only used when compulsory and where this is enforced. There are improved designs available, but these can be difficult to obtain and carry a higher cost.

A number of interviews raised the suggestion that a form of risk homeostasis might be operating, where provision of PPE, such as harnesses, makes workers feel safer, therefore leading them to increase their exposure to risk in other ways. This is as discussed by 
Rasmussen (1997). Although the nature and extent of this remain to be confirmed, the accident studies indicated the possibility that in some situations this might be present. This emphasises the important message that despite the current focus of risk management in the industry on PPE, it should only be a last resort. Elimination or reduction of risk through other means, eg design, should be the priority.

There appears to be a significant opportunity with the design of materials and equipment to improve safety, with many of the problems relatively straightforward to overcome. However, this will need much better liaison within the supply-purchase chain. The manner in which this operates at present appears to stifle developments.

\subsection{Originating influences}

Originating influences, especially inadequacies with risk management, were considered to have been present in almost all (94\%) of the accidents. The originating influences in construction accidents are the high level determinates of the nature, extent and existence of immediate causes of accidents. Elsewhere, these influences have sometimes been referred to using terminology such as 'root causes'. It seems very clear that these influences do affect safety on construction sites. However, this research has demonstrated that the effects of these influences are subtle and that it is difficult to trace through to these when exploring the causation of an individual incident. Hence the different vocabulary preferred here.

\section{Construction design and processes}

Elimination or reduction of risks through design or alternative methods of construction is highly desirable. Frequently, construction design and construction process are interlinked, with the process being dictated by the design and decisions from the design team. Taking this 
into account, this research found that up to half of the 100 accidents examined could have been mitigated through a design change. In many of the cases, this could have been by preassembly, with the construction work moved off-site (Gibb, 1999). An example of this is an accident where an electrician was installing cables in a ceiling void and suffered a deep laceration to his arm from an exposed metal ceiling grid. An improved design would have avoided sharp protrusions, making allowance for installation and subsequent maintenance tasks. Moreover, pre-assembly of the above-ceiling services would have allowed the operation to be performed at a more convenient working height, without the workspace limitations encountered on site. It is recognised, however, that pre-assembly may introduce risks elsewhere (eg during transportation from manufacturing facility to site).

A significant finding from the follow-up investigations was that although some members of the construction design community are fervent advocates of designing for safety, these are the exception rather than the rule. Many designers are still failing to acknowledge their influence on the safety of the construction process. Where recognition of influence does exist, other conflicting priorities are cited, such as client requirements and cost. Underlying this response by designers is deep-seated custom and practice and an absence of safety education and training (Carpenter et al, 2000).

Some managerial interviewees mentioned that, in their experience, design and build project arrangements allow many of the barriers to designing with safety in mind to be overcome. This is because the contractual arrangements place the responsibility for both design and construction elements within a single project team, leading to shared goals, improved communication, and a better environment for new ideas to flourish. Although it appears intuitive that such arrangements should help address some of the problems with conventional 
project management structures, it was not possible to examine the detailed pros and cons of different contractual arrangement within this research.

Although half of the accident studies might have been prevented by design, the corollary is that half could not. The proportions here might be subject to sampling bias, due to selection of less serious accidents but, nonetheless, many of the incidents were caused by commonplace hazards and activities that will continue to occur on site whatever design changes might be made. The widespread presence of the many generic safety risks accompanying construction needs to be tackled before the benefits of design improvements will be realised.

There are many aspects of the construction process that are left to the discretion of site personnel. This is fine detail beyond that specified in design instructions. It was apparent from the interviews that tension exists over precisely where the boundary should lie in the division of responsibility between the design and contractor teams. Whoever does assumes responsibility, an important indication from this research is that safety currently does not receive adequate consideration in the decision making. No evidence was found of use of sources of advice, such as available on the risks associated with alternative designs and construction methods (Ove Arup \& Partners, 1997).

\section{Project management}

A clear influence from problems with project management was identified in only a quarter of the accident studies, although this is likely to have been because the precise effects are difficult to corroborate. This research supports previous findings (Gyi et al, 1999) regarding the negative implications for safety that arise from the sub-contracting arrangements within 
the industry. This leads to problems with blurred responsibility and difficulties with communication between one contractor and another.

Deficiencies in project management and planning can lead to difficulties with the project schedule. These in turn result in time pressure on all involved within a project, with subsequent problems such as trade overlap, crowded workspaces and reduced attention to detail. Around 1 in 10 of the accident studies were in the context of project scheduling problems. Although a feature of these incidents, the extent to which this may have been causal is uncertain.

\section{Risk management}

It is not particularly surprising that Table 5 should identify deficiencies in risk management in most of the 100 accidents studied. Accidents invariably involve an inadequately controlled risk, indicative of a management failing. Echoing the findings from many years of accident research, it is again noteworthy that most of the 100 accidents studied for this project could have been foreseen and were preventable.

As a part of each accident study, the relevant method statements were requested, with consideration then given to how the incident mapped on to these. It is interesting to note the significant proportion of accidents for which no method statement was applicable. This was often because the accident happened away from any particular construction task; when the accident-involved individual was moving around site; or engaged in an activity regarded as a core skill. Similarly, it was frequently the case that no risk assessment had been undertaken for the accident activities, despite this being a legal requirement, even for activities 'off-task' 
Where risk assessments did exist, these often formed part of a method statement, the applicability of which to actual work circumstances was often limited.

The findings from the accident studies and focus groups leads to the conclusion that there is a pervasive failure of the industry to engage in effective risk management. Where risk assessment had been attempted, this was largely a paper exercise, unlikely to have any real effect. It appears that an over reliance on PPE as a control is used as a substitute for eliminating hazards and reducing risks through more direct means. When accidents do happen, there is limited accident investigation, undertaken for the wrong reasons. The findings of investigations frequently contain an over attribution to 'chance', and a tendency for over apportionment of 'blame'. Another important shortcoming of the accident investigation processes in the industry is an absence of effective remedial action after a problem has occurred.

\section{Client and economic influences}

There was little direct evidence of the influence of client requirements or the economic climate on the accidents studied for this research. While these undoubtedly do affect construction safety, there was only one instance in the dataset where it seemed requests from clients might have led to an increased risk. This was with respect to a high frequency of architect instructions.

“We've had over a thousand architect instructions on this site because of disagreements within the outside design team. A good design should normally have no more than 300. The changes were for a range of reasons .... the area was not properly designed in the first place. The design didn't work or they had changed 
their mind from the original specification.” (29 year old project manager, accident 25)

The economic climate in which construction activity takes place affects competition for projects, pricing, availability of labour and so forth. All of these are likely to impinge on safety.

\section{Safety education and training}

Problems with safety education and training have been discussed above, in connection with site-based personnel. When it comes to the education and training of architects, designers, engineers and surveyors, other research (Carpenter et al, 2000) has identified that the provision of health and safety education in construction related university degrees in Britain is poor. This was, however, in the face of inadequate requirements for health and safety education by accreditation bodies which regulate the professions. A need exists across the industry, encompassing designers and suppliers, as well as site based personnel, to raise awareness and understanding of the generic safety risks that are commonplace in construction.

\section{Concluding Remarks}

Through the use of focus groups and detailed studies of 100 accidents, this research has collected information on the factors involved in construction accidents in Great Britain. Based on this information, a model of causal influences has been proposed, which acknowledges the adaptive socio-technical system construction operations present. As with previous accounts (HSE, 1978, 1988; Whittington et al, 1992), the model includes the immediate circumstances in accidents, such as unsafe acts by workers, poor communication, 
problems with site conditions, and shortcomings with equipment and materials. In line with increasing recognition over the past decade of the importance of wider systemic factors in construction safety (Whittington et al, 1992; Gyi et al, 1999; Brabazon et al, 2000; Bomel, 2001; Carpenter et al, 2001; Suraji et al, 2001), the model goes on to indicate the pathways through which originating organisational, managerial and design influences shape the circumstances on site, giving rise to the conditions in which accidents occur. The focus groups, corroborated by findings from the accidents studies, indicated particular problems at the originating level with risk management and limited attention to the safety implications of construction design.

Achieving a significant and sustained reduction in accidents will require concerted efforts directed at the hierarchy of causal influences. Important points are:

- Safety needs to be owned and integrated across the project team, from designers and engineers through to skilled trade personnel and operatives.

- Other research has shown how the lead given by front line supervisors has a strong influence on safety performance. Worker participation in managing safety is important, to generate ideas and to build ownership and responsibility.

- Where safety depends on communication and coordination, it is important that a robust safe system of work is established. This should not be left to chance.

- Significant improvement is required with standards of site layout and housekeeping. Principal contractors are well placed to raise expectations of acceptable practice.

- Greater attention should be given to the design and selection of tools, equipment and materials. Safety, rather than price, should be the paramount consideration.

- Greater sophistication is needed with the design and use of PPE. PPE is often uncomfortable and impedes performance. Forcing workers to wear PPE when risks are 
not present can be counterproductive. PPE should be a last rather than first resort for risk management.

- There is a need across the industry for a more intelligent engagement with risk management. Emphasis should be on actively identifying and managing risks, starting at the point of their inception, rather than treating risk assessment as merely a paper exercise.

- Construction should be encouraged to benchmark its safety practices against other industries. The excuse that construction is inherently 'different' in some way from other industries does not stand up to scrutiny.

- Greater opportunity should be taken to learn from failures, with implementation of accident investigation procedures, both by employers and regulatory bodies, structured to reveal contributing factors earlier in the causal chain.

- It is important for 'safety' to be disassociated from 'bureaucracy'.

- Frequently, safety does not have to come at a price. Where there are cost implications, regulatory bodies and trade associations need to work to make sure there is a level playing field with respect to tendering.

Most of these changes depend on achieving widespread improvement in understanding of safety and risk management. This research has indicated that at present, a large majority of those working in construction in Great Britain, both on and off site, have only a superficial appreciation of health and safety considerations.

While the accidents studied for this research achieved a good spread of accidents across construction sectors and accident categories, there are areas of construction underrepresented in the study. Although accidents to self-employed workers or those working for small subcontractors were included, these were almost all within the context of projects run by a large 
principal contractor. The research did not encompass the small builders, working in isolation, generally regarded as having an especially poor health and safety record. The challenge of improving safety within these small enterprises is considerable.

\section{Acknowledgements}

The research reported in this paper was funded by the Health and Safety Executive. Any opinions and/or conclusions expressed, however, are those of the authors alone and do not necessarily reflect HSE policy.

\section{References}

BOMEL, 2001, Improving health and safety in construction - Phase 1: data collection, review and structuring. HSE Contract Research Report 387/21 (HSE Books: Sudbury, Suffolk).

Brabazon P, Tipping A and Jones J, 2000, Construction health and safety for the new millennium. HSE Contract Research Report 313/2000 (HSE Books: Sudbury, Suffolk).

Bust P, Gibb A F G and Haslam R A, 2004, Manual handling during installation of highway kerbs. Applied Ergonomics, this issue, ????-????.

Carpenter J, Williams P and Charlton Smith N, 2000, Identification and management of risk in undergraduate construction courses. HSE Contract Research Report 392/2000 (HSE Books: Sudbury, Suffolk). 
Chew D C E, 1988, Effective occupational safety activities: findings in three Asian developing countries. International Labour Review, 127, 111-125.

Chi C-F, Chang T-C and Ting H-I, 2004, Fatal occupational falls in the construction industry in Taiwan, 1994-1997. Applied Ergonomics, this issue, ????-????.

Duff A R, Robertson I T, Phillips R A and Cooper M D, 1994, Improving safety by the modification of behaviour. Construction Management and Economics, 12, 67-78.

Gibb A G F, 1999. Off-site fabrication (Whittles: Caithness).

Gibb A, Hide S, Haslam R and Hastings S, 2001, Identifying the root causes of construction accidents - discussion. Journal of Construction Engineering and Management, 127, 3.

Gyi D E, Haslam R A and Gibb A G F, 1998, Case studies of occupational health management in the engineering construction industry. Occupational Medicine, 48, 263-271.

Gyi D E, Gibb A G F and Haslam R A, 1999, The quality of accident and health data in the construction industry: interviews with senior managers. Construction Management and Economics, 17, 197-24.

Health and Safety Commission (HSC), 2001, Managing Health and Safety in Construction, Construction (Design and Management) Regulations 1994 (HSE Books: Sudbury, Suffolk) HSG 224. 
Health and Safety Commission (HSC), 2003, Health and Safety Statistics Highlights 2002/03 (HSE Books: Sudbury, Suffolk).

Health and Safety Executive (HSE), 1978, One hundred fatal accidents in construction (HMSO: London).

Health and Safety Executive (HSE), 1988, Blackspot construction: a study of five years fatal accidents in the building and civil engineering industries (HMSO: London).

Health and Safety Executive (HSE), 1996, A guide to the Reporting of Injuries, Diseases and Dangerous Occurrences Regulations 1995 (HSE Books: Sudbury, Suffolk).

Health and Safety Executive (HSE), 2002, Revitalising health and safety in construction (HSE Books: Sudbury, Suffolk).

Heinrich H W, Petersen D and Roos N, 1980, Industrial accident prevention: A safety management approach (McGraw-Hill: New York), 5th edition.

Hide S, Hastings S, Gyi D, Haslam R and Gibb A, 2001, Using focus group data to inform development of an accident study method for the construction industry. In: Contemporary Ergonomics 2001 (edited by: M A Hanson) (Taylor \& Francis: London), pp 153-158.

Hinze J and Russell D B, 1995, Analysis of fatalities recorded by OSHA. Journal of Construction Engineering and Management, 121, 29-214. 
Hoonakker P, Loushine T, Carayon P, Kallman J, Kapp A and Smith M J, 2004, Accidents, injuries, worker's compensation and safety in construction industry: the effort/results paradox. Applied Ergonomics, this issue, ????-????.

Hunting K L, Nessel-Stephens L, Sanford S M, Shesser R, and Welch L S, 1994, Surveillance of construction worker injuries through an urban emergency department. Journal of Occupational Medicine, 36, 356-364.

Kisner S M and Fosbroke D E, 1994, Injury hazards in the construction industry. Journal of Occupational Medicine, 36, 137-143.

Kletz T, 2001, Learning from accidents (Gulf: Oxford), $3^{\text {rd }}$ edition.

Loughborough University and UMIST, 2003. Causal factors in construction accidents (HSE Books: Sudbury, Suffolk), RR 156.

Ove Arup \& Partners, 1997, CDM Regulations - work sector guidance for designers (CIRIA: London).

Rasmussen J, 1997, Risk management in a dynamic society: a modelling problem. Safety Science, 27, 183-213.

Reason J, 1995, A systems approach to organisational error. Ergonomics, 38, 1708-1721. 
Saloniemi A and Oksanen H, 1998, Accidents and fatal accidents - some paradoxes. Safety Science, 29, 59-66.

Simard M and Marchand A, 1994, The behaviour of first-line supervisors in accident prevention and effectiveness in occupational safety. Safety Science, 17, 169-185.

Snashall D, 1990, Safety and health in the construction industry. British Medical Journal, 31, $563-564$.

Suraji A, Duff A R, 2001, Identifying the root causes of construction accidents - discussion. Journal of Construction Engineering and Management, 127, 3.

Suraji A, Duff A R and Peckitt S J, 2001, Development of causal model of construction accident causation. Journal of Construction Engineering and Management, 127, 337-344.

Svedung I and Rasmussen J, 2002, Graphic representation of accident scenarios: mapping system structure and the causation of accidents. Safety Science, 40, 397-417.

Whittington C, Livingston A and Lucas D A, 1992, Research into management, organisational and human factors in the construction industry. HSE Contract Research Report 45/1992 (HMSO: London). 